\title{
High School Students' Perspectives of Participating in a STEM-Related Extracurricular Programme
}

\author{
Peter Mtika * \\ School of Education, King's College, University of Aberdeen, Aberdeen, United Kingdom
}

This article reports on secondary school students' perspectives of participating in science, technology, engineering and mathematics (STEM) related extracurricular activities in six secondary schools in Scotland. The extracurricular activities aimed at supporting students in developing knowledge of STEM subjects and confidence in their preparation for high school examinations, post-secondary schooling, and the world of work. The study used a mixed-methods design. This entailed collecting data using qualitative semi-structured interviews, focus group discussion and a quantitative questionnaire. Findings indicate that students viewed extracurricular activities positively.

OPEN ACCESS

Edited by:

Andy Townsend,

University of Nottingham,

United Kingdom

Reviewed by:

Amanda Washington Lockett, University of Pennsylvania,

United States

Marsha E. Modeste,

Pennsylvania State University,

United States

Justine T. MacLean,

University of Edinburgh,

United Kingdom

*Correspondence:

Peter Mtika

p.mtika@abdn.ac.uk

Specialty section:

This article was submitted to

Leadership in Education,

a section of the journal

Frontiers in Education

Received: 04 June 2019 Accepted: 02 September 2019 Published: 13 September 2019

Citation:

Mtika P (2019) High School Students' Perspectives of Participating in a STEM-Related Extracurricular Programme. Front. Educ. 4:100. doi: 10.3389/feduc.2019.00100 They felt that the activities they participated in made a difference in their overall development. STEM related extracurricular activities provided students with relevant subject knowledge, wider learning opportunities and confidence in their own abilities, thereby contributing toward academic and social development. Students also reported increased knowledge of post-schooling opportunities. The activities resonated with the Scottish Curriculum for Excellence (CfE), thereby complemented formal learning.

Keywords: curriculum for excellence, extracurricular activities, high school, mixed methods, private-public collaboration, STEM subjects

\section{INTRODUCTION}

Internationally, extracurricular activities (ECAs) such as sport, drama, debate, volunteering, academic revision clubs etc., have gained an important place in students' school life to the extent that many schools are making significant efforts of offering different types of ECAs to their learners (Straw et al., 2011; Mtika and Payne, 2014; Seow and Pan, 2014). ECAs are a means of ensuring that all students, irrespective of individual circumstances such as socio-economic background, have the opportunity to succeed in school (Cazden, 2012). ECAs can support young people by providing them with necessary opportunities for academic and interpersonal development in preparation for post-secondary schooling and the world of work (Roulin and Bangerter, 2013; Fischer and Theis, 2014; Mtika and Payne, 2014; Brooks et al., 2015; Greenbank, 2015). Within the Scottish policy context, widely accessible academically focused ECAs have the potential to help reduce the attainment gap caused by poor socio-economic backgrounds of learners (Sosu and Ellis, 2014).

However and in most cases, ECAs tend not to be free. As such, only students who have financial means can benefit by participation. Where ECAs are fee-based, young people from deprived backgrounds are unlikely to access extra academic and personal development. This can effectively contribute to ECAs as vehicle for reproduction of inequality in society (Covay and Carbonaro, 2010; Thomson, 2019). The provision of free ECAs therefore constitute a socially just and more accessible way of supporting all the young people to develop necessary academic, social, and employability skills (Scottish Government, 2018). 
This study is concerned with students' perspectives of taking part in science, technology, engineering and mathematics (STEM) ECAs, and the potential connections of ECAs with the Scottish Curriculum for Excellence (CfE). The study explores the perspectives of high school students who participated in a free STEM-related extracurricular activity intervention programme (see Table 1). The rationale for the study is that learning is not exclusively restricted to formal settings within classroom contexts (Coulangeon, 2018). High school students aged 15-17 years, from six comprehensive secondary schools in one part of Scotland took part in a range of coordinated school-based ECAs. The areas of focus of the ECAs were academic subject enrichment, career readiness and exploration, and preparation for $\mathrm{FE} / \mathrm{HE}$.

\section{Extra-Curricular Activities (ECAs)}

Globally, many education systems have embedded ECAs within their educational support structure for students. In the UK, ECA initiatives targeting high school students have included studentadult mentoring (Mtika and Payne, 2014), and STEM (science, technology, engineering and mathematics) clubs (Straw et al., 2011), among others. These engage young people in learning STEM subjects in creative ways outside the curriculum. Other popular youth schemes in the UK, such as Brownies and Girls Guide, tend to focus exclusively on the social and interpersonal development of primary school students. These programmes require participants to pay a small fee to access them. This means that not all families may be able to enroll their children. Children who may be interested in these programmes but fail to attend on the basis of "fees prohibition" may therefore not have adequate opportunities to develop their social and cultural capital which may be important for their success in school as well as when they join the world of work (Smith, 2000-2009; Darling et al., 2005).

There are numerous benefits of participating in ECAs. Taking part in ECAs can influence students' success in their school subjects (George, 2012), and subsequent career prospects (Fujita, 2006). Kelepolo (2011) found that students who participated in ECAs were well prepared for higher or further education and they achieved better grades. In connection with the notion of social and cultural capital, participation in ECAs predicted a higher likelihood of college attendance, civic consciousness, reduced dropout rate (Moran, 2017). Furthermore, Darling et al. (2005) found out that students who took part in ECAs were better able to establish meaningful social networks with significant adults. This is necessary as it contributes to the development of social and cultural capital (Kaufman and Gabler, 2004; Darling et al., 2005). Additionally, the process of developing new friendship with others contributes to one's own identity exploration and formation of self-concept of young people (Darling et al., 2005). Clearly, the skills and attributes developed or enhanced through participation in ECAs are useful for post-compulsory schooling and employability. Those who develop these skills are better prepared when they move out of the secondary sector and start living independently, such as when they enroll in university education.

In terms of conditions under which ECAs can be beneficial, it is important that young people themselves need to be highly motivated and willing to take part. Darling et al. (2005) found that young people who already had a positive self-concept were likely to take part in ECAs. In relation to duration, longer period of participation in ECAs is likely to be more successful than one-off short-term activities. Straw et al. (2011) in their study in England found that participation in ECAs of over a year delivered more positive results than shorter programmes.

In this study, I was interested in understanding the potential benefits for students who participated in an intervention programme involving free ECAs in one part of Scotland. The areas of focus of the ECAs were academic enrichment, career readiness and exploration, and preparation for FE/HE. The research also investigates the potential resonance between ECAs and the Scottish Curriculum for Excellence (CfE). The paper aims to add to knowledge about means of supporting young people to fulfill their potentials in life. The specific research questions are:

a) What were the students' perspectives of participating in a STEM related intervention programme of ECAs in one region in Scotland?

b) How did ECAs meet the objectives of the Scottish Curriculum for Excellence in relation to the four principles and outcomes [successful learners, confident individuals, effective contributors, and responsible citizens]?

In the next sections, I discuss the study context, research design, findings, and conclusion from the study.

\section{School-Based Extracurricular in Scotland}

The intervention programme involving ECAs was implemented by six comprehensive secondary schools in Scotland. Scotland has developed an arguably ambitious curriculum covering 3-18 years old called "Curriculum for Excellence" (CfE). CfE aims to improve learning opportunities for students by enhancing attainment and ensuring that all children are prepared properly for the future (Scottish Government, 2014). CfE emphasizes the importance of learning experiences, which enable the development of the whole person to become successful learners, confident individuals, effective contributors, and responsible citizens (Scottish Government, 2014).

Pedagogical approaches espoused within CfE include active learning, outdoor learning, cooperative and collaborative learning and peer learning. These approaches support individualized and contextualized learning. CfE highlights the view that:

\footnotetext{
"Every child and young person is entitled to develop skills for learning, skills for life and skills for work, with a continuous focus on literacy, and numeracy and health and wellbeing" (Scottish Government, 2008, p. 15).
}

One of the main ways of delivering different skills for work, such as employability, leadership, independent living within the CfE, is through partnership, and encouraging young people to volunteer or undertake work placements or study tours in various settings (Scottish Government, 2009b). CfE considers ECAs as equally useful for developing skills beyond specific academic subjects. ECAs implemented by schools could therefore contribute to 
TABLE 1 | Summarized details of STEM related extracurricular activities.

\section{Details of STEM related extracurricular activities}

First Year

Second year
Team building event for students at an outdoor center. The steering committee facilitated this event. The students traveled to Badaguish Outdoor Center where they worked across schools as part of team and confidence building.

Series of 2-h after-school seminars, called STEMinars [Science, Technology, Engineering, Mathematics, Information, Navigation, and Revision Sessions]. These STEMinars initially took place on a weekly basis but later, they took place fortnightly. Mainly volunteers in STEM from the project sponsoring company facilitated them. They lasted five months.

Career talks from science professionals including STEM ambassadors. Members of a national STEM programme who volunteered to work with schools facilitated these talks. They provided support and encouragement as well as role models to young people.

Employability skills workshop, job shadowing, a live kidney transplant video link, a cardiac classroom, company site tour, and visit to a Center for Health Science. These provided students the opportunity to observe how professionals used various STEM and health skills in the world of work. HI-STOP Diabetes prevention group activity. This diabetes raising awareness activity ran for three months. It involved students from each of the participating school coming up with a project related to diabetes prevention. The group projects were shared at an open seminar attended by the wider community and parents/guardians.

Student-adult mentoring. This involved pairing students with adults working in STEM fields. They planned their own meetings within the mentor dyad. They also contacted each other via telephone, email, and text messaging. Mentoring lasted eight months. the development of the "whole person" as required by the CfE. Furthermore, school-based ECAs could be viewed as a response to the notion that "learning outside the classroom can help to make subjects more vivid and interesting for pupils and enhance their understanding" (Ofsted, 2008, p. 7).

$\mathrm{CfE}$ is underpinned by an understanding that it cannot be delivered in schools alone and there is a need to build partnerships between schools and the wider business and public sectors. For example, the Scottish Government (2008) noted that:

\footnotetext{
"Partnerships with colleges, youth work services, the voluntary sector and employers will open up a wide range of motivating choices, based upon the experiences and outcomes, to meet the needs of all young people" (Scottish Government, 2008, p. 40).
}

Subsequently, both the private and public sectors have a contribution to make toward CfE as future employers of the young people (Scottish Government, 2008). As such, employers can help young people to develop a range of skills through collaborating with schools (Scottish Government, 2009b). Any opportunities available to students to engage in various forms of wider learning, out-of-school hours, such as field trips, and linking students to external providers of specific training can support students in developing appropriate skills, values, and attitudes (Eshach, 2006). Expansive learning through ECAs can therefore complement formal learning (Coulangeon, 2018). An intervention programme of ECAs explored in this paper represent one way in which six secondary schools worked closely with a multinational company through a private-public partnership to offer young people opportunities for wider learning (Scottish Government, 2014). The areas of focus of the ECAs were academic enrichment, career readiness and exploration, and preparation for $\mathrm{FE} / \mathrm{HE}$.

This paper is interested in understanding what the students developed from participating in ECAs and whether the programme of ECAs they participated in complemented the formal school curriculum in Scotland.

\section{The Study}

This study is based on an intervention programme of ECAs (see Table 1), which were implemented in six high schools in Scotland as part of a global initiative originating in the United States. The ECAs aimed to enhance the engagement of young people in the Science, Technology, Engineering, Mathematics (STEM) disciplines. The Activities also aimed to improve young people's attitudes and skills in preparation for Further Education/Higher Education (FE/HE) and the world of work.

The philosophy of the ECAs programme appeared to align with the Scottish Government's educational policies that aim to support schools to build stronger links with local employers. The "Curriculum for Excellence Building the Curriculum 4 Skills for Learning, Life and Work" document states that teachers will be supported to deliver creative, engaging and workrelevant learning (Scottish Government, 2009a). The Scottish Government's "Partnership with Employers" resource developed by the "Determined to Succeed" programme aims to showcase best practice of effective employer partnerships taking place within Scottish schools (Scottish Government, 2009b).

The programme attempted to achieve its aims by the private sponsoring company forming a private-public partnership locally with six secondary schools, a Further Education (FE), and/or Higher Education (HE) institution, and relevant key local organizations. Since participation in the programme in Scotland was free, it was likely that all interested students, could participate. The target population for the ECAs were students from six comprehensive secondary schools in secondary grades 4 (S4), and year grade 5 (S5). Entry to these schools is open to all, without regard to academic achievement. The catchments for these schools are diverse in terms of socio-economic status. The main challenges facing young people in the local area and broadly in the region were in connection with rurality within a wide geographical area (Mtika and Payne, 2014). According to the programme implementation team, there was a lack of awareness of STEM opportunities among the students and a trend for school leavers to go directly into employment rather than onto higher 
education. It is understandable that the latter trend could have been due to the lower academic scores that students achieved when they left high school.

ECAs were implemented through a steering group comprising representatives of five organizations; namely, the sponsoring private company; the Scottish Community Foundation; local authority; a university; an FE college and an enterprise organization. The students who participated in the ECAs did so voluntarily. The target population for the project in Scotland were secondary school students. Each secondary school had a named teacher who was a contact person and coordinator of the programme at a school level. The steering committee implemented a number of formal ECAs as part of the programme (see Table 1).

This programme was designed to provide students with what Eccles et al. (2003, p. 885) described as "opportunities to engage in different tasks that promote learning of valued skills, forming social bonds with non-familial adults and prosocial peers." In first year, activities focused on improving student' skills, such as communication, working with others, understanding the workplace and the employees' responsibilities. In second year, students were assigned an adult mentor to support them in their career interests and school subjects. Students received transport support so they could attend planned activities.

\section{MATERIALS AND METHODS}

This research was part of an independent evaluation of the ECAs implemented in one part of Scotland. The research was a synergistic mixed-methods design involving quantitative and qualitative data using questionnaires, semi-structured interviews/focus group interviews (Creswell and Plano Clark, 2011). However, most of the data collected were qualitative in nature. The use of mixed-methods in this study allowed for possible corroboration, integration and consolidation of research findings (Guest, 2012).

\section{Participants, Data Collection and Data Analysis}

This study adhered to British Educational Research Association (2018). The University of Aberdeen College of Arts and Social Sciences Ethical committee approved the study after reviewing the necessary project materials for compliance. Further, to ensure adherence to ethics of informed consent for students under the age of 18, parents and guardians of all potential research participants received briefing about the research through an information sheet. The information sheet outlined what involvement in the project would entail. Parents and guardians were free to grant or refuse permission for their child to take part in the study. In addition, each student was sent an information and consent sheet about the research. Students and their parents/guardians were assured of confidentiality (Lankshear and Knobel, 2004). It was highlighted that taking part in the study would support the evaluation of the project as well as contribute to a better understanding of the dynamics of school-based ECAs.

The students who took part in the programme over the 2 years were homogenous in terms of ethnicity, identifying themselves as white/Europeans. The programme had more female students than male students. The average age of students at the time they exited the programme was 17 years. The sample in the study was small and self-selected. Therefore, it is not representative of the population of high school students in Scotland. Due to these limitations, it is important to regard the study as exploratory in nature.

For data collection from students from the 6 participating schools, Likert type and open-ended questions were used at three stages during the programme implementation: preprogramme survey $n=67$ (40 female; 27 male), endof-year one survey $n=47$ (25 female; 12 male), and exit survey $n=31$ (24 female; 7 male). The programme coordinator was responsible for administering questionnaires. A small number of students were also interviewed in three smaller focus groups $n=23$ (16 female and 7 male). These interviews were audio-recorded and transcribed by a sub-contracted individual.

In addition to interviewing students, three male teachers who acted as school coordinators and contacts for three of the six schools on the programme were also interviewed as part of data collection. These teachers were of varying experience.

Understandably, there was noticeable attrition on the programme across the 2 years, with 67 students starting the programme, and by the end of the programme, there were only 31 students. The attrition was due to students who left high school for further education or the world of work. A short survey was conducted with students who had left the programme but were still in school. For the students who completed this survey, the predominant reasons for leaving the programme were lack of interest, and long distance some of the students had to travel for ECA events. Only aggregate attrition data is available. In future, it would be important to be able to disaggregate data in accordance with the school students were attending.

Data analyses were mainly through descriptive statistical analysis and thematic analysis. Concerning the quantitative data, aggregation of responses in relation of frequency of occurrence was a predominant approach. For thematic analysis, an open coding approach was utilized to examine data transcripts for clusters of semantic units in relation to the research questions (Langdridge, 2004). The author was responsible for both quantitative and qualitative data analysis.

\section{RESULTS}

This study was concerned with students' perspectives of taking part in specific ECAs (see Table 1) and whether the ECAs met the objectives of the Scottish CfE. In the next sections, I present findings of the students' perspectives. Qualitative data from surveys is presented using pseudonyms, while focus group data is not linked with any personal identifier. 


\section{Students' Perspectives of Participating in Extracurricular Activities}

The findings from students and teachers interviewed show that students benefited in a number of ways from participating in the programme of ECAs.

\section{Increased Knowledge of Post-schooling Opportunities}

The students felt that they increased their knowledge of further education/higher education opportunities. They also increased their belief that further education/higher education is accessible to them. For example, a number of students noted:

It has given me a further understanding of what I have to do to apply for university and I feel more confident now (Laura, end of year 1 survey).

It has drastically increased my awareness of what jobs in sciences (James, end of year-one survey).

It has made me want to take advanced higher Biology \& Higher human Biology to get the career I want (Monica, exit survey).

I have learnt about different careers and I have broadened my choices for the future whilst gaining confidence (Tania, end of year-one survey)

In addition, a teacher from one of the schools made the following comments:

I think our kids certainly have a very informed decision as to what they are going to do in higher education now. They have made choices into science that they would not have otherwise... (Science teacher interview).

More importantly, 52\% (35) of the students at the preprogramme phase, $87 \%$ (41) at end of year 1, and $74 \%$ (23) at end of the programme hoped to go to university after completing Advanced Higher Education in secondary year grade 6 (S6). This suggests that the students believed that university was accessible to them.

Students attributed their increased knowledge to STEMinars, which were implemented as part of ECAs. Two students remarked:

I think some of the STEMinars were structured like a lecture, that's kind of getting you used to university and college, it's more lectures and it's getting used to that (end of year 1 student interview).

The STEMinars have helped me remember parts of my courses that I did understand or could not remember all of (Alicia, end of year-one survey).

Through mentoring, students' broadened their awareness about Higher Education as the comments show:

It taught me that you need a bit more than grades to get into university. You need to have volunteering and extra personal skills (end of programme student interview).

It is very much more of an informed decision, for instance, one of our boys [name] is very academic, really into science and technology and he wanted to be involved in aerospace engineering. Because he got a mentor who was involved in aerospace engineering [he] now knows that he absolutely positively wants to do it (science teacher interview).

\section{Knowledge of How School Learning Applies to the World of Work}

Students indicated that ECAs, such as job shadowing, helped them to gain practical knowledge and awareness of how school learning applied to the world of work. Students commented on how they were beginning to develop the connection between school learning and the world of work. The comments below illustrate this:

... They showed us how people have to use Pythagoras to work out such things and show how physics is used in a [science industry during factory visit] (end of year-one student interview).

I was not going to take a science at higher but I took Biology higher because I realized how they are important (Chloe, exit survey).

Students felt that a live video link to a kidney surgery in the United States gave them insights into how their learning applies in real life medical settings.

We had a chance to be able to speak to the surgeon as well and ask questions to him (end of programme student interview).

The students' understanding of the connection between school learning and the world of work through the programme meant that they were now better able to appreciate what their teachers were teaching them.

It makes you appreciate the teachers more for teaching you because we just think they are evil [author's emphasis] because they have to teach you all this stuff... but you will need it in later life (end of year 1 student interview).

\section{Confidence in Abilities}

Findings on the students' perceived confidence on a range of soft skills were collected through a Likert type questionnaire at three stages during the programme. Self-reported findings suggest that ECAs made an impact on students' soft skills (see Table 2).

Based on the results, $70 \%$ or over of the students expressed being "confident/very confident" in working on their own, sharing opinions with other, working in a team at the end of the programme.

I am now much more confident. I have new friends and had great fun in the process (James, exit survey).

I am more confident person, and more aware of what to expect in the future (Cathy, exit survey).

Some of the students associated their growing confidence in abilities to a range of ECAs they had participated. For example, during a team-building event, students were asked to work across schools as part of team and confidence building. They had not met the students from the other schools before and they were basically strangers to each other. A student noted: 
TABLE 2 | Students' perceptions of their confidence.

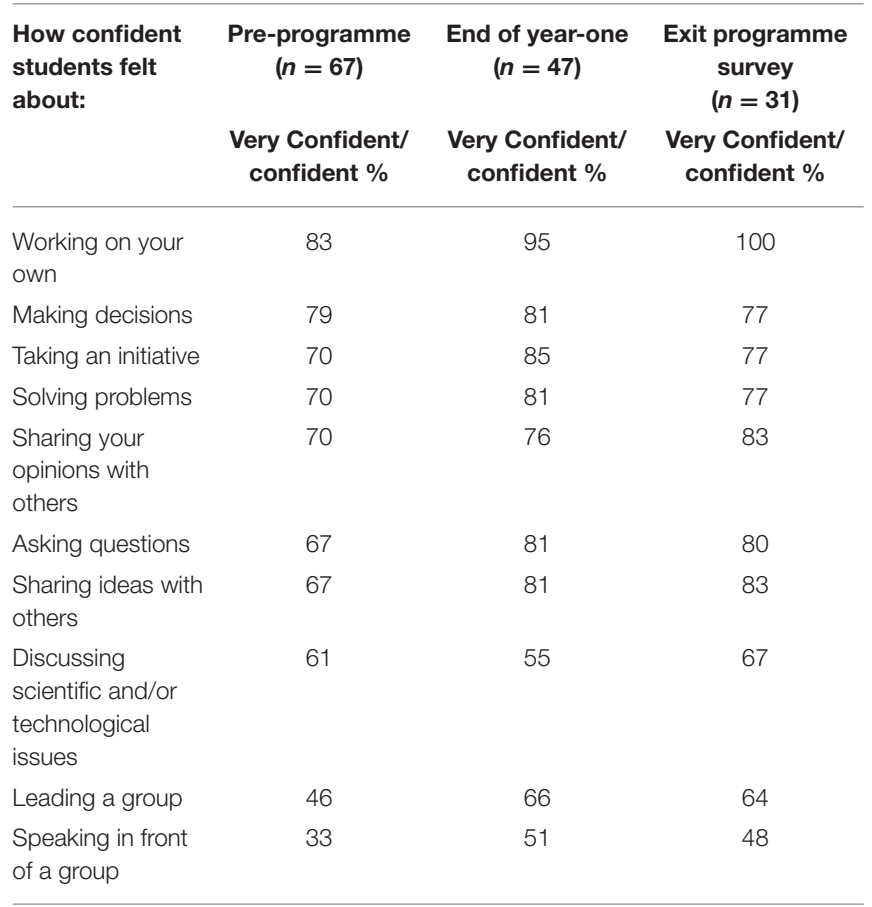

I know that during [team building] I had no one from my school that was in my group. You, kind of, had to build up the confidence to actually go over and talk to someone and make friends with them (end of year-one student interview).

During STEMinars, a similar approach of requiring students not to sit next to students from the same school was adopted. A student commented:

In the STEMinars, we were told that we were not allowed to sit in our school groups because we were really good at sitting in our school groups (end of year-one student interview).

In addition, the HI-STOP extracurricular activity, which focused on diabetes raising awareness, contributed to confidence in connection with sharing ideas with others and speaking in front of a group. A student remarked:

I thought it was really nice that we got to do the whole thing... we had somebody who helped us with the filming, but we had to do everything, we had to do all the editing, even our speech and answering questions it was nice to have the control, and feel that's all our work (end of programme student interview).

It would appear that different ECAs helped the students to develop and/or enhance various skills, which would be useful in future. However, only $64 \%$ indicated being very confident/confident in leading a group at the end of the programme. Further, only $48 \%$ were confident or very confident speaking in front of a group post-intervention.

Having considered students' perspectives of participating in ECAs, the next section explores any connections between ECAs and the Scottish Curriculum for Excellence.

\section{ECAs and the Curriculum for Excellence}

The importance of examining possible resonance between ECAs and Scottish Curriculum for Excellence stems from the view that learning is not restricted to formal curriculum settings alone, but also, through other arrangements (Coulangeon, 2018). In this study, I explore ECAs in relation to the four principles and outcomes of CfE, namely, successful learner, confident individual, effective contributor and responsible citizen.

\section{Successful Learner}

Within CfE, "successful learner" relates to the "ability to use literacy, communication and numeracy skills; use of technology for learning; thinking creatively and independently; learning independently and as part of a group; making reasoned evaluations; and linking and applying different kinds of learning in new situations" (Scottish Executive, 2004). In relation to this, the findings in this study showed that topics included in the STEMinars helped students to gain a better understanding of science subjects studied in secondary school.

The STEMinars allowed us to go in-depth with parts of science that we did not really understand, and boosted our performance [in exams] (end of year-one student interview).

When I was doing biology and chemistry, I knew I was behind because I was not very good at chemistry, I never have been, never will be. However, [STEMinars] made me understand it a lot better... it made it easier to understand (end of year-one student interview).

Their presentation skills have become very good, they've also developed an understanding of how stuff they learn in school fits in with the world of work and further study (Principal Teacher interview).

A student who had missed part of the school biology sessions relied on inputs from STEMinars during exams. The student noted:

The genetics [STEMinars] came up in the examinations, I missed most of the genetics lessons because I was on holiday, so I was not really taught so when it came up in the examinations, I remembered it from the STEMinars (end of year 1 student interview).

\section{Confident Individuals}

Within CfE, "confident individual" is about one's ability to "relate to others and manage oneself; pursuing a healthy and active lifestyle; being self-aware; developing and communicating own beliefs and view of the world; living as independently as one can; assessing risk and taking informed decisions; and achieving success in different areas of activity" (Scottish Executive, 2004). While the programme of ECAs did not address all these attributes, an employability skills workshops helped students to develop their confidence in many ways. Students were given opportunities to take part in a simulated job interview. A teacher noted during one of the interviews, how students were being interviewed by total strangers but they held their own.

I sat in that room and six of them were individually called in and were interviewed; it really blew me away because they 
were being interviewed by somebody in Washington... That alone would terrify anybody, but the students held their own (Principal teacher interview).

I think it has helped me to develop confidence skills and learnt more about my chosen science (Louisa, end of yearone survey).

Increased my confidence with others in a group and I learned about what I can expect when I work (Richard, end of yearone survey).

\section{Effective Contributors}

Within CfE, "effective contributors" relates to the ability to "communicate in different ways and in different settings; working in partnership and in teams; taking the initiative and leading; applying critical thinking in new contexts; creating and developing; and solving problems" (Scottish Executive, 2004).

This theme relates to the idea of confidence in abilities explored in the first research question. In addition to the findings around confidence in abilities, the team-building event helped students to work together more effectively. A teacher from one of the schools commented.

[Students] had to work in groups at [Badaguish out-door center for team-building]; they were very good at identifying what it was that they themselves were good at, were they good at organizing, were they good at encouraging other people to take part. They all played their role in those groups quite well or they contributed what they could to those groups quite well (head of technical subjects' teacher interview).

The poster preparation and presentation during STEMinars were helpful in ensuring that students were becoming effective contributors.

From the presentation, there is learning about working as a team, doing research together, and because we were meeting up out of school in our own time, it is more responsibility arranging things ourselves (end of year-one student interview).

Activities relating to the HI-STOP extracurricular activity, whereby groups of students developed their diabetes knowledge and later, presented their projects to parents and the local community demonstrated that the students were becoming effective contributors on an important health topic. A teacher noted the concerted efforts by students to contribute to the Diabetes task.

The [HI-STOP] Diabetes activity project took a lot of work, a lot of planning, a lot of organization, and when they realized that they had finished that and that they had completed that, and it was a serious achievement that gave them a lot of confidence in their ability to do something like that again (Principal teacher interview).

This demonstrated students' growing confidence in contributing effectively to a collaborative venture.

The programme totally changed the way I am, my subjects, punctuality, motivation, and my confidence at leadership as well as much more (Robert, exit survey).
Through participation in a range of activities, students were acquiring relevant attributes of being effective contributors.

\section{Responsible Citizens}

Within CfE, "responsible citizens" relates to the ability to "develop knowledge and understanding of the world and Scotland's place in it; understanding different beliefs and cultures; making informed choices and decisions; evaluating environmental, scientific and technological issues; and developing informed, ethical views of complex issues"(Scottish Executive, 2004, p. 12).

The HI-STOP Diabetes activity fulfilled a range of the CfE capacities mainly responsible citizenship. The aim of this particular activity was not only for students to learn about healthy living and understanding Type 2 Diabetes, but also to disseminate the message to their peers. This was completed over several weeks supported by a range of visiting arts specialists. Students' dissemination activities included an advertisement, a film documentary, rock and roll song, which were presented at a competition for all six school teams to an invited audience. It was further noted that the materials from the diabetes task were going to be made available to other schools for students who were not part of the programme to also benefit.

Clearly, these findings suggest that some of the ECAs resonated and supported the development of students in line with the CfE principles.

\section{DISCUSSION AND CONCLUSION}

This study was concerned with students' experiences of ECAs and the potential connections between the ECA programme and the Scottish CfE. Generally, there seems a positive opinion of their experiences with ECAs. It is important to note that the students who took part in the study were self-selected and therefore not representative of the entire student population. As noted in the literature (e.g., Darling et al., 2005), most of the students who take up ECAs tend to be those from higher social class and more positively oriented to school and for them, taking part in ECAs is a way of confirming their motivation. However, it was not possible to determine the social class and the motivation for the students in this study. Nonetheless, the study provides some basis for ensuring that ECAs are widely available to all types of students within school settings (Coulangeon, 2018).

The findings from this analysis provide a number of interesting points for discussion. In the first place, the students from the six high schools in one region of Scotland described their experiences of ECAs as largely positive. In relation to the specific findings, the programme could be perceived to be aligned with the Scottish Government efforts to closing the attainment gap (Scottish Government, 2014). For example, STEMinars, which were offered during the programme were focused on enhancing students' knowledge and skills in specific subjects within the sciences. This additional tutoring and other contextualized learning enabled participating students to further develop their cognitive understanding in science subjects. As the findings have shown, students who took part in STEMinars identified direct cognitive benefits from it. Arguably, extending the provision of this type of ECA could more likely augment the 
national curriculum and improve students' results (Eshach, 2006; Scottish Government, 2014; Coulangeon, 2018). This academic focused activity could contribute toward closing the attainment gap (Sosu and Ellis, 2014).

The findings suggest that the students who took part in the programme appeared to have increased their knowledge of postschooling opportunities and application process. This was an important finding given that participants lived in an area which was largely rural lacked awareness of STEM opportunities (Mtika and Payne, 2014). It is possible that the students extended their knowledge about post-schooling options. As also demonstrated in England, involvement in STEM ECAs raised students' interest in STEM subjects and careers, and enhancement of generic skills such as team-working, problem solving which are useful for the world of work (Straw et al., 2011).

The findings which showed that the programme enhanced the students' knowledge of how school learning applied to the world of work imply that some of the contents within science subjects which sometimes were previously perceived to be a bit abstract had been given a practical orientation, thereby stimulating students' learning. The contextualized learning through STEMinars, company tours and job shadowing appeared to have given meaning to some of the contents in the formal school subjects and curriculum (Eshach, 2006). It could be argued that when these students reach a stage when they would be considering career prospects in the form of $\mathrm{FE} / \mathrm{HE}$ courses of interest, the knowledge developed on the programme would form the basis of their perspectives.

The other significant findings pointed to students' enhanced confidence in abilities. Similarly, Fujita (2006) found that ECAs underpinned a number of functions ranging from academic, social, physical, and cognitive development. In this case, increased confidence seemed to develop during a number of activities such as when students were required to interact with people from different schools, e.g., during the team-building event or STEMinars. This not only enabled students to develop their confidence, but also, it inevitably helped them to expand their friendship networks (Kaufman and Gabler, 2004).

In relation to potential resonance between ECAs and CfE, the findings showed that some of the activities contributed to CfE in various ways. They helped the students to enhance various skills such as employability and interpersonal skills in generalconfidence, working with others, sharing opinions, ideas with others, leading a group, literacy, communication skills, problem

\section{REFERENCES}

British Educational Research Association (2018). Ethical Guidelines for Educational Research. London: British Educational Research Association.

Brooks, B. A., Floyd, F., Robins, D. L., and Chan, W. Y. (2015). Extracurricular activities and the development of social skills in children with intellectual and specific learning disabilities: extracurricular activities and social development. J. Intel. Disabil. Res. 59, 678-87. doi: 10.1111/jir.12171

Cazden, C. B. (2012). A framework for social justice in education. Int. J. Edu. Psychol. 1, 178-98. doi: 10.4471/ijep.2012.11 solving. In particular, the activities helped the students to develop understanding of STEM subjects.

However, while the programme appeared to have supported the students in relation to CFE especially during their examinations, this study has not provided any tangible data for drawing claims on whether the activities contributed to improved performance in any formal examinations. This is an interesting area for future studies. It may be necessary to think also of having a control group in future studies to better examine the impact of the programme on attainment. Nonetheless, evidence from elsewhere has shown that participation in certain ECAs does indeed lead to better academic results (Darling et al., 2005; Kelepolo, 2011).

Looking to the future, efforts to offer free ECAs and widening student participation is vital. It is important that ECAs are seen to be complementary to the formal curriculum to justify funding investment (Scottish Government, 2014; Coulangeon, 2018).

\section{DATA AVAILABILITY}

The datasets generated for this study are available on request to the corresponding author.

\section{ETHICS STATEMENT}

The studies involving human participants were reviewed and approved by The University of Aberdeen College of Arts and Social Sciences (CASS) Ethical committee approved the study after reviewing the necessary project materials for compliance. Written informed consent to participate in this study was provided by the participants' legal guardian/next of kin.

\section{AUTHOR CONTRIBUTIONS}

The author confirms being the sole contributor of this work and has approved it for publication.

\section{FUNDING}

This research was part of an independent evaluation of a project funded by the Academy for Educational Development (AED), now incorporated as part of FHI 360. Fran Payne and I carried out the work on which this paper is based. Fran retired before the completion of the project and is sadly deceased. I extend my gratitude to her for the mentorship. 
J. Leisure Res. 37, 51-76. doi: 10.1080/00222216.2005.119 50040

Eccles, J. S., Barber, B. L., Stone, M., and Hunt,. J. (2003). Extracurricular activities and adolescent development. J. Soc. Issues 59, 865-889. doi: 10.1046/j.0022-4537.2003.00095.x

Eshach, H. (2006). Science Literacy in Primary Schools and Pre-Schools. Dordrecht: Springer.

Fischer, N., and Theis, D. (2014). Extracurricular participation and the development of school attachment and learning goal orientation: the impact of school quality. Dev. Psychol. 50, 1788-1793. doi: 10.1037/a00 36705

Fujita, K. (2006). The effects of extracurricular activities on the academic performance of junior high students. Undergraduate Res. J. Human Sci. 5. Available online at: https://www.academia.edu/8558846/The_Effects_of_ Extracurricular_Activities_on_the_Academic_Performance_of_Junior_High_ Students_Kimiko_Fujita_The_Masters_College

George, S. B. (2012). A study of the relationships between extracurricular participation in selected North Carolina high schools and student achievement as determined by cumulative grade point average (Doctoral dissertation) Appalachian State University, Boone, NC: United States.

Greenbank, P. (2015). Still focusing on the 'essential 2:1': exploring student attitudes to extra-curricular activities. Edu. Train. 57, 184-203. doi: 10.1108/ET-06-2013-0087

Guest, G. (2012). Describing mixed methods research: an alternative to typologies. J. Mixed Methods Res. 7, 141-151. doi: 10.1177/1558689812461179

Kaufman, J., and Gabler, J. (2004). Cultural capital and the extracurricular activities of girls and boys in the college attainment process. Poetics 32, 145-168. doi: 10.1016/j.poetic.2004.02.001

Kelepolo, E. N. (2011). The relationship between participation in extracurricular activities and Utah's proficiency assessments of students in a suburban school district (doctoral dissertation). University of Nevada, Las Vegas, NV, United States.

Langdridge, D. (2004). Introduction to Research Methods and Data Analysis in Psychology. Harlow: Pearson Education.

Lankshear, C., and Knobel, M. (2004). Teacher Research: From Design to Implementation. Maidenhead: Open University Press.

Moran, J. (2017). The impact of extracurricular activity on teacher job satisfaction (doctoral dissertation). Youngstown State University, Youngstown, $\mathrm{OH}$.

Mtika, P., and Payne, F. (2014). Student-adult mentoring relationships: experiences from a Scottish school-based programme. Edu. Res. 56, 436-452. doi: 10.1080/00131881.2014.965571

Ofsted (2008). Learning Outside the Classroom. London: Ofsted. Available online at: https://www.lotc.org.uk/wp-content/uploads/2010/12/Ofsted-Report-Oct2008.pdf (accessed May 9, 2019).
Roulin, N., and Bangerter, A. (2013). Students' use of extra-curricular activities for positional advantage in competitive job markets. J. Edu. Work 26, 21-47. doi: $10.1080 / 13639080.2011 .623122$

Scottish Executive (2004). A Curriculum for Excellence: The Curriculum Review Group. Edinburgh: Scottish Executive.

Scottish Government (2008). Curriculum for Excellence: Building the Curriculum 3 - A Framework for Learning and Teaching. Edinburgh: Scottish Government.

Scottish Government (2009a). Curriculum for Excellence: Senior Phase Management Board Discussion Paper. Edinburgh: Scottish Government.

Scottish Government (2009b). Curriculum for Excellence: Building the Curriculum 4 - Skills for Learning, Skills for Life and Skills for Work. Edinburgh: Scottish Government.

Scottish Government (2014). Child Poverty Strategy for Scotland: Our Approach 2014 - 2017. Edinburgh: Scottish Government.

Scottish Government (2018). Children, Education in Out-of-School Activities: Research Findings. Edinburgh: Scottish Government.

Seow, P., and Pan, G. (2014). A literature review of the impact of extracurricular activities participation on students' academic performance. J. Edu. Bus. 89, 361-366. doi: 10.1080/08832323.2014.912195

Smith, M. K. (2000-2009). Social Capital, the Encyclopedia of Informal Education. Available online at: http://infed.org/mobi/social-capital/ (accessed June 7, 2018).

Sosu, E., and Ellis, S. (2014). Closing the Attainment Gap in Scottish Education. Report of the Joseph Rowntree Foundation. New York, NW: Joseph Rowntree.

Straw, S., Hart, R., and Harland, J. (2011). An Evaluation of the Impact of STEMNET's Services on Pupils and Teacher. Slough: National Foundation for Educational Research.

Thomson, R. (2019). Education, Inequality and Social Class: Expansion and Stratification in Educational Opportunity. London: Routledge.

Conflict of Interest Statement: The author declares that the research was conducted in the absence of any commercial or financial relationships that could be construed as a potential conflict of interest.

Copyright (c) 2019 Mtika. This is an open-access article distributed under the terms of the Creative Commons Attribution License (CC BY). The use, distribution or reproduction in other forums is permitted, provided the original author(s) and the copyright owner(s) are credited and that the original publication in this journal is cited, in accordance with accepted academic practice. No use, distribution or reproduction is permitted which does not comply with these terms. 